\title{
UMA ANÁLISE CRÍTICA ENTRE OS CURRÍCULOS DOS CURSOS DE CIÊNCIAS CONTÁBEIS NOS PAÍSES DO MERCOSUL E O PROPOSTO PELA ONU/UNCTAD/ISAR ${ }^{1}$
}

\section{A CRITICAL ANALYSIS BETWEEN THE CURRICULUM COURSE OF ACCOUNT- ING IN MERCOSUR COUNTRIES AND THE PROPOSED BY UN/UNCTAD/ISAR}

\author{
Giovanna Tonetto Segantini' ${ }^{2}$ \\ Mestra pelo Programa Multiinstitucional e Inter-regional de Pós-Graduação em Ciências Contábeis \\ Universidade Federal do Rio Grande do Norte \\ giovanna.ufrn@gmail.com \\ Clayton Levy Lima de Melo \\ Doutorando pelo Programa Multiinstitucional e Inter-regional de Pós-Graduação em Ciências Contábeis \\ Universidade Federal do Rio Grande do Norte \\ clayton_levy@hotmail.com

\section{Edzana Roberta Ferreira da Cunha Vieira Lucena} \\ Doutoranda pelo Programa Multiinstitucional e Inter-regional de Pós-Graduação em Ciências Contábeis \\ Universidade Federal do Rio Grande do Norte \\ edzana@hotmail.com

\section{José Dionísio Gomes da Silva} \\ Professor do Programa Multiinstitucional e Inter-regional de Pós-Graduação em Ciências Contábeis \\ Universidade Federal do Rio Grande do Norte \\ dionisio@ufrnet.br
}

\begin{abstract}
RESUMO
A harmonização das normas contábeis tornou-se uma necessidade dos usuários externos e internos da informação contábil, uma vez que passaram a atuar em diversos mercados e a prestar contas aos usuários com necessidades variadas, pois o mercado cada vez mais globalizado exige profissionais preparados para atuar dentro e fora do seu país. Visando isso, a ONU/UNCTAD/ISAR desenvolveu um Currículo Mundial para servir de referência para os cursos de Ciências Contábeis, buscando prover conhecimentos internacionais de normas contábeis independentemente do país responsável pela formação do profissional. Assim, o objetivo geral do artigo foi analisar e comparar a adequação dos currículos dos cursos de ciências contábeis de quatro universidades do MERCOSUL, sendo uma de cada país, com o currículo proposto pela ONU/UNCTAD/ISAR. As universidades selecionadas foram: Facultad de Ciencias Econômicas de la Universidad de Buenos Aires (Argentina); Faculdade de
\end{abstract}

\footnotetext{
${ }^{1}$ Artigo recebido em: 28/06/2013. Revisado por pares em: 29/06/2013. Recomendado para publicação em: 21/07/2013 por Orleans Silva Martins (Editor Geral). Publicado em: 23/07/2013. Organização responsável pelo periódico: UFPB.

2 Endereço: Universidade Federal do Rio Grande do Norte, Departamento de Ciências Contábeis, Campus Universitário, CEP: 59.072 970, Natal/RN.

DOI: http://dx.doi.org/10.18405/recfin20130106
} 
Economia, Administração e Contabilidade da Universidade de São Paulo (Brasil); Universidad Nacional de Asunción (Paraguai); e Facultad de Ciências Econômicas y de Administración de la Universidad de la República (Uruguai), e suas matrizes curriculares foram comparadas com o Currículo Mundial proposto pela ONU/UNCTAD/ISAR. Os resultados indicam que a similaridade entre os currículos das quatro universidades selecionadas com o proposto pela ONU/UNCTAD/ISAR é alta, existindo, em média, 76,71\% de semelhança entre as matérias dos currículos. Por ser apenas uma recomendação, as universidades pesquisadas demonstraram possuir certa flexibilidade na elaboração de seus currículos.

Palavras-Chave: Harmonização. Currículo Internacional. Educação Contábil.

\begin{abstract}
The harmonization of accounting standards has become a need of external and internal users of accounting information as it began to operate in different markets and accountable to users with varying needs. However, the market increasingly globalized requires trained professionals to work within and outside the country in order that the UN/UNCTAD/ISAR has developed a global curriculum for the courses in accountancy, which provides a world of accounting regardless of country of professional training. Given this, the general aim of the article is to analyze and compare the suitability of the curricula of schools of accountancy in four universities in the MERCOSUL, one from each country, with the curriculum proposed by the UN/UNCTAD/ISAR. The work was done, initially, a literature search on accounting harmonization, accounting profession in the MERCOSUL and global curriculum. They were then selected four universities, Facultad de Ciencias Económicas de la Universidad de Buenos Aires (Argentina); School of Economics, Business Administration and Accounting from the University of Sao Paulo (Brazil), Universidad Nacional de Asuncion (Paraguay) and Faculty of Science Economic y de Administración de la Universidad de la República (Uruguay), due to present their master curricula on their websites, and finally a comparison was made to the curriculum proposed by the UN World/UNCTAD/ISAR. The results indicated that the similarity between the curricula of four universities selected in relation to the proposed UN/UNCTAD/ISAR is high, with an average of $76.71 \%$ similarity of materials between the curricula. Keywords: Harmonization. International Curriculum. Accounting Education.
\end{abstract}

\title{
1 INTRODUÇÃO
}

A formação de blocos econômicos é uma consequências resultantes do processo de globalização da economia e dos mercados mundiais. Com isso, a harmonização contábil internacional tornou-se uma necessidade para melhorar o fluxo da informações entre seus diversos usuários, reduzindo assim tempo e custos nas negociações. Todavia, com as barreiras internacionais cada vez menores, o mercado tem exigindo profissionais qualificados para atuarem dentro e fora do seu país. E cabem às instituições de ensino superior a responsabilidade de formar profissionais capacitados para atuar no mercado internacional.

Para diminuir a disparidade do ensino da Contabilidade do mundo, a ONU/UNCTAD/ISAR desenvolveu uma sugestão de currículo para que os cursos superiores de Ciências Contábeis possam basear a sua grade curricular, na tentativa de que os bacharéis em Contabilidade possuam formação na qual os conhecimentos necessários para a profissão sejam semelhantes, independente do país de origem.

A ONU/UNCTAD/ISAR, dentre vários pontos, ressalta a importância de se criar um Currículo Mundial de estudos em Contabilidade, já que esse currículo serviria de referência e, também, reduziria tempo e custos em negociar acordos de reconhecimento mútuo. Além disso, como foi apontado por Erfurth e Domingues (2008, p. 2), “quanto maior for a similaridade entre as grades 
curriculares adotadas por certo país e as grades curriculares internacionais, tanto maior será a evidência de harmonização na educação".

Devido ao processo de harmonização e convergência internacional às Normas Internacionais de Contabilidade (NIC) editadas pelo International Accounting Standards Board (IASB), tem-se discutido a possibilidade de um ensino uniforme para os cursos de Ciências Contábeis, o que passaria, obrigatoriamente, pela discussão de um currículo mínimo para todos os países participantes do processo de convergência.

Apesar de se considerar a importância da discussão de melhorias no ensino da Contabilidade em todos os países que contemplem o atual processo de convergência, não se deve desconsiderar a importância de cada instituição e dos professores para a melhoria do processo educativo. Dessa forma, qualquer modelo de currículo para os cursos em todo o mundo não deve ser tratado de forma centralizadora e rígida. Esse processo necessita da contribuição mútua de órgãos institucionais e de cada instituição de ensino responsável por esse processo. Essa opção implicaria na utilização do modelo misto de organização curricular.

Assim, a busca por uma boa qualidade de cursos de Ciências Contábeis do Brasil, que reflitam a tendência mundial de convergência, deve passar por uma discussão ampla com a participação de órgãos internacionais (IASB), nacionais (como o Ministério da Educação e Cultura - MEC), órgãos da classe contábil (como o Conselho Federal de Contabilidade - CFC - e o Instituto dos Auditores Independentes do Brasil - IBRACON), professores, sociedade e Instituições de Ensino Superior (IES). Com base no exposto, e como forma de se iniciar essa discussão, propõe-se a seguinte questão de pesquisa: as matérias oferecidas nos currículos da Facultad de Ciencias Econômicas de la Universidad de Buenos Aires (UBA), da Faculdade de Economia, Administração e Contabilidade da Universidade de São Paulo, da Universidad Nacional de Asunción e da Facultad de Ciências Econômicas y de Administración de la Universidad de la República possuem similaridades com as matérias oferecidas pelo currículo proposto pela ONU/UNCTAD/ISAR?

Assim, esse artigo tem como objetivo geral analisar e comparar a adequação dos currículos dos cursos de Ciências Contábeis da Facultad de Ciencias Econômicas de la Universidad de Buenos Aires (Argentina), da Faculdade de Economia, Administração e Contabilidade da Universidade de São Paulo (Brasil), da Universidad Nacional de Asunción (Paraguai) e da Facultad de Ciências Econômicas y de Administración de la Universidad de la República (Uruguai) com o currículo proposto pela ONU/UNCTAD/ISAR. Adicionalmente, tem como objetivos específicos: apresentar e comentar a harmonização contábil; apontar a relevância da educação superior no processo de harmonização contábil; identificar os blocos do conhecimento elencados no Currículo Mundial; e apresentar a situação da profissão contábil nos países do MERCOSUL.

\section{REFERENCIAL TEÓRICO}

Neste tópico é abordada a harmonização internacional das normas contábeis, como consequência dos fenômenos da globalização, o papel da educação superior diante dessas mudanças, as sugestões para um Currículo Mundial apresentadas pela ONU/UNCTAD/ISAR e as características dos países do MERCOSUL, do ponto de vista da profissão contábil, dando ênfase à formação dos profissionais contábeis.

\subsection{Harmonização Internacionais das Normas Contábeis}

A Contabilidade, segundo Niyama (2009, p. 15), "por ser uma ciência social aplicada, é fortemente influenciada pelo ambiente em que atua". Desta forma, fatores culturais, econômicos, históricos, legais e políticos refletem no sistema contábil de cada país (LEMES; CARVALHO, 2009). Com isso, o conjunto de normas, práticas e interpretações contábeis tende a divergir de país para país, "significando dizer que o lucro de uma empresa brasileira não seria o mesmo se adotadas as 
práticas contábeis de outros países, dificultando sua compreensão devido à falta de uniformidade" (NIYAMA, 2009, p. 15).

A formação de blocos econômicos e o aquecimento da economia em termos globais permitiram o crescimento e o desenvolvimento de multinacionais em vários países, além do aumento de volume de investimentos estrangeiros nos mercados de capitais internos, o que demandou uma informação que fosse compreensiva por todos, independentemente do país. Diante desse cenário, sentiu-se a necessidade de criar as normas contábeis internacionais, que permitiria o entendimento da Contabilidade por todos, uma vez que a informação fornecida por ela estaria em um formato de compreensão mundial (CZESNAT; CUNHA, 2009).

Nesse sentido, Hawarth (apud Polhmann, 1995, p. 2) destaca que,

A necessidade de normas contábeis internacionais existe em dois níveis: primeiro, as empresas multinacionais necessitam delas para assegurar que os resultados de cada um de seus segmentos sejam reportados em uma base compatível; segundo, os usuários das demonstrações financeiras necessitam dessas normas para que possam assegurar de que as demonstrações financeiras de todas as companhias, independente do país em que estão domiciliadas, sejam comparáveis e reflitam os fatos econômicos.

Nesse contexto, as diferenças entre as normas contábeis de cada país seriam diminuídas com a harmonização contábil, facilitando o entendimento das informações contidas nas demonstrações contábeis (CZESNAT; CUNHA, 2009). Isso se justifica pois é preciso que a Contabilidade, considerada por Niyama (2009) a linguagem dos negócios, esteja exposta aos usuários de forma compreensiva, podendo ser usufruída da melhor forma possível, levando-os à tomada de decisão (CZESNAT; CUNHA, 2009). Assim, de maneira a acompanhar essa evolução, a educação contábil tem significativo impacto em relação à qualidade e tipo de informação disponível aos seus usuários.

\subsection{Educação Contábil Internacional}

Diante do processo de harmonização, Czesnat e Cunha (2009) defendem a ideia de que é preciso que os conhecimentos dos profissionais da área contábil estejam em consonância com as normas internacionais, para que saibam administrar, explicar e aplicá-los quando necessário. Contudo, é preciso disponibilizar a eles o conhecimento, e é ai que entra a responsabilidade das universidades, pois são essas instituições que formam os profissionais contábeis.

Complementando essa ideia, Erfurth e Domingues (2008, p. 2) afirmam que "as Instituições de Ensino Superior (IES) são responsáveis perante o mercado de trabalho, pela formação de profissionais capazes de desempenhar suas atividades de maneira adequada". Por esta razão, a maneira pela qual as IES proporcionam a formação de seus estudantes é por meio da identificação de competências exigidas pelo mercado de trabalho, moldando seus projetos pedagógicos e sua estrutura curricular de acordo com as necessidades do mercado.

Com a economia e o mercado mundial globalizado, profissionais competentes e capazes de emitir informações para diversos usuários são cada vez mais exigidos. Para diminuir a disparidade da Contabilidade no mundo e o conhecimento dos contabilistas recém formados, a ONU/UNCTAC/ISAR desenvolveu uma sugestão de currículo para que os cursos superiores de Ciências Contábeis possam basear sua grade curricular.

A iniciativa de um currículo mínimo mundial é uma tentativa de que os bacharéis em Ciências Contábeis possuam uma formação na qual os conhecimentos necessários para a profissão sejam semelhantes, independentemente do país de formação do profissional. Contudo, essa adoção não deve ocorrer de maneira rígida, sem considerar as características regionais, sociais e econômicas dos locais aonde as IES estão inseridas. 
Como forma de atender à necessidade atual mundial de convergência às NIC, deve ocorrer uma discussão que envolva todos os participantes do processo educativo. Isto significaria uma união de esforços entre órgãos internacionais como o IASB, o Financial Accounting Standards Board (FASB), os órgãos de classe de cada país envolvido e os órgãos nacionais responsáveis pelo ensino superior (no caso do Brasil, CFC, IBRACON e MEC) e as IES, além de professores e sociedade envolvida.

Dessa forma, a discussão da organização curricular atenderia a um modelo misto, com a participação de todos os setores envolvidos no processo educacional, considerando as atuais necessidades mundiais e, ao mesmo tempo, as características regionais e a participação de professores, instituições de ensino e sociedade.

Assim, não seria discutida a exigência de uma organização curricular única para todo o mundo, atitude considerada prejudicial às características próprias de cada país. Dessa forma, a educação contábil no Brasil continuaria atendendo aos requisitos exigidos pela Lei № 9.394/1996, que determina a flexibilização do currículo através da elaboração do Projeto Político Pedagógico (PPP) de forma participativa, com a contribuição de docentes, discentes, corpo administrativo da IES e comunidade, conforme Lei № 9.394/1996 e Resolução № 10 do MEC, CNE/CES, que instituiu as diretrizes curriculares nacionais para o curso de graduação em Ciências Contábeis.

Para Veiga (2004), os currículos podem ser organizados de duas formas: a primeira, denominada currículo-coleção, baseia-se em orientações didáticas rígidas e centralizadas por algum órgão reguladores do ensino; a segunda, currículo-integração, envolve o processo de auto regulação do currículo pelas instituições de ensino, com a forte atuação de professores, alunos e comunidade onde a instituição se insere, sem a interferência de um órgão central. No caso estudado neste trabalho, percebe-se que forma de se estudar e discutir os currículos a nível mundial envolve os dois modos de organização citados acima.

\subsection{Proposta de Currículo Mundial da ONU/UNCTAC/ISAR}

A décima sexta sessão do Intergovernmental Working Group of Experts on International Standards of Accounting and Reporting (ISAR), que foi realizada em fevereiro de 1999 na cidade de Genebra, adotou um guia de requerimentos para a formação e a qualificação profissional em Contabilidade. O guia incluía um currículo modelo para a educação do profissional em Contabilidade. A principal intenção do desenvolvimento desse currículo era apresentar para a comunidade internacional as principais disciplinas técnicas que um indivíduo deveria saber para se tornar um profissional contábil (UNCTAD, 2009).

O intuito de criar uma referência para a qualificação do profissional contábil era de fomentar, a qualificação desses profissionais para melhor atuar e servir a economia global, além de promover a harmonização dos requisitos para a formação profissional. Desta forma, a harmonização iria fechar as lacunas nos sistemas nacionais de formação, reduzir os custos de mútuos acordos de reconhecimento e aumentar o comércio internacional de serviços de Contabilidade (UNCTAD, 2009).

O Currículo referência é composto de duas categorias: a primeira, TD 05, é um guia para sistemas nacionais de qualificação de contadores; a segunda, TD 06, é composta por um conjunto de áreas do conhecimento necessárias para a educação profissional dos contadores. Assim, o modelo de plano de estudos publicado pelo TD/B/COM.2/ISAR/6 em 1999, foi revisado em 2003 com o documento Revised Model Accounting Curriculum (MC), o qual descreve de forma detalhada os conteúdos de cada um dos blocos de conhecimento (ERFURTH; DOMINGUES, 2008).

Os blocos de conhecimento definidos pelo ISAR/UNCTAD, detalhados no TD 21, são apresentados conforme Quadro 1. 


\begin{tabular}{|c|c|c|c|}
\hline $\begin{array}{l}1 \text { Conhecimento } \\
\text { Administrativo e } \\
\text { Organizacional }\end{array}$ & $\begin{array}{l}2 \text { Tecnologia de } \\
\text { Informação }\end{array}$ & $\begin{array}{l}3 \text { Conhecimentos } \\
\text { Contábeis, Financeiros e } \\
\text { assuntos afins }\end{array}$ & $\begin{array}{l}4 \text { Conhecimento (avançado) } \\
\text { em Contabilidade, Finanças e } \\
\text { assuntos afins }\end{array}$ \\
\hline $\begin{array}{l}\text { a) Economia; } \\
\text { b) Métodos quantitativos } \\
\text { e estatísticos para as em- } \\
\text { presas; } \\
\text { c) Políticas empresariais, } \\
\text { de estruturas organizaci- } \\
\text { onais básicas, e comporta- } \\
\text { mento organizacional; } \\
\text { d) Funções e práticas ad- } \\
\text { ministrativas, e gestão de } \\
\text { operações; } \\
\text { e) Marketing; } \\
\text { f) Mercados internacio- } \\
\text { nais. }\end{array}$ & $\begin{array}{l}\text { a) Tecnologia de infor- } \\
\text { mação; }\end{array}$ & $\begin{array}{l}\text { Curso básico de Contabili- } \\
\text { dade, auditoria, tributação e } \\
\text { assuntos afins. } \\
\text { a) Contabilidade básica; } \\
\text { b) Contabilidade financeira; } \\
\text { c) Contabilidade financeira } \\
\text { avançada; } \\
\text { d) Contabilidade gerencial - } \\
\text { conceitos básicos; } \\
\text { e) Tributação; } \\
\text { f) Sistemas de informações } \\
\text { contábeis; } \\
\text { g) Direito comercial e em- } \\
\text { presarial; } \\
\text { h) Fundamentos sobre audi- } \\
\text { toria; } \\
\text { i) Finanças empresariais e } \\
\text { gestão financeira; } \\
\text { j) Módulo sobre integração } \\
\text { do conhecimento: a capstone. }\end{array}$ & $\begin{array}{l}\text { a) Demonstrações financeiras } \\
\text { avançadas e Contabilidade in- } \\
\text { dustrial; } \\
\text { b) Contabilidade gerencial } \\
\text { avançada; } \\
\text { c) Tributação avançada; } \\
\text { d) Direito empresarial avan- } \\
\text { çado; } \\
\text { e) Auditoria avançada; } \\
\text { f) Finanças empresariais avan- } \\
\text { çadas e Administração finan- } \\
\text { ceira; } \\
\text { g) Estágio Contábil; }\end{array}$ \\
\hline
\end{tabular}

Fonte: UNCTAD (2009).

A proposta principal desse documento, como foi colocada por Czesnat e Cunha $(2009$, p.5), "é servir como base para as instituições de ensino superior formular os seus próprios currículos, buscando uma uniformização dos estudos de Contabilidade", ou seja, a ISAR propôs uma estrutura curricular mundial para orientar as instituições de ensino superior a desenvolver planos de estudos semelhantes, favorecendo um ensino em Contabilidade a nível mundial.

\section{$2.4 \quad$ MERCOSUL}

Com a economia mundial globalizada, a tendência comercial tem sido a formação de blocos econômicos. Estes blocos são criados com a finalidade de facilitar o comércio entre os países membros. O Mercado Comum do Sul (MERCOSUL) é um bloco de integração instituído pelo Tratado de Assunção, firmado em 26 de março de 1991, pela República Argentina, República Federativa do Brasil, República do Paraguai e República do Uruguai, denominados "Estados Parte” (MRE, 1991).

A formação do MERCOSUL exigiu um amplo esforço dos países que se integraram (Brasil, Argentina, Uruguai e Paraguai), no sentido de compatibilização e harmonização de políticas, legislações e procedimentos, nas diversas áreas de atuação da sociedade, dentre as quais se inclui a Contabilidade (POHLMANN, 1995). Nesse contexto, a Contabilidade se destaca como instrumento gerador de informações para a tomada de decisão, que a partir da harmonização contábil pode se tornar uma "linguagem" a nível mundial, o que evidência a importância da Contabilidade dentro do processo de estruturação e implementação do MERCOSUL.

\subsubsection{Argentina}

O profissional de Contabilidade na Argentina é denominado de Contador Público e o exercício da profissão está estabelecido pela Lei № 20.488, de 23 de maio de 1973, que abrange as Ciências Econômicas em geral (ARGETINA, 2009). Essa Lei determinou a filiação obrigatória aos Conselhos Profissionais, os quais controlam o exercício dos profissionais Contábeis. Os conselhos profissionais, 
apesar de terem sido criados por lei, são entidades de natureza jurídica privada, independentes do Estado, seja política, administrativa ou economicamente (KRAEMER, 2005).

A formação do contador Público, tomando por base o programa da Facultad de Ciencias Económica de La Universidad de Buenos Aires, a mais conceituada do país, tem como currículo mínimo de graduação um composto de 38 disciplinas, das quais 8 são optativas, perfazendo 184 horas semanais, totalizando, aproximadamente, 3.000 horas-aula ao longo de todo o curso, que é dividido em 2 ciclos: a) ciclo geral - com duração de dois anos, abrangendo disciplinas básicas que possibilitam ao aluno o ingresso no curso de Contador Público; e b) ciclo profissional - que abrange as disciplinas especializadas (FCE UBA, 2007).

Como exposto pela Facultad de Ciencias Económica de La Universidad de Buenos Aires, o plano curricular está estruturado da melhor forma possível, possibilitando a formação de profissionais que atendam às novas realidades impostas pelo mercado de trabalho.

\subsubsection{Brasil}

A profissão contábil no Brasil foi regulamentada pelo Decreto-Lei $N^{\circ} 9.295$, de 27 de maio de 1946, e suas alterações posteriores. Por meio desse mesmo Decreto-Lei, foram criados o Conselho Federal de Contabilidade (CFC) e os Conselhos Regionais e Contabilidade (CRC) (ROSA, 1998). O CFC é o órgão responsável pelo controle do exercício profissional, bem como por editar princípios e normas contábeis e exigir o seu cumprimento.

A profissão contábil está dividida em duas categorias profissionais: a) técnico em Contabilidade - contabilistas que são formados em Contabilidade em nível de segundo grau; e b) contador profissional formado em nível superior. Ambos estão habilitados a exercer a profissão contábil, desde que devidamente registrados em um dos CRC.

A formação dos contadores no Brasil é regulamentada pelo Conselho Nacional de Educação (CNE), na sua Resolução N 10, de 16 de dezembro de 2004. Tomando como base o currículo de graduação da Faculdade de Economia, Administração e Contabilidade da Universidade de São Paulo (FEA-USP), o curso deve ter no mínimo 3.000 horas-aula, que deverão ser integralizadas em, no mínimo, 8 semestres e, no máximo, 14 semestres. Para a conclusão desse curso, os alunos devem cursar 37 disciplinas obrigatórias, correspondente a 156 créditos, e 12 optativas livres, correspondendo a 24 créditos, sendo essas últimas direcionadas às áreas de interesse próprio (FEA USP, 2009).

\subsubsection{Paraguai}

No Paraguai, a profissão contábil é regulamentada pela Lei №371, de 06 de dezembro de 1972, que regulamenta o exercício profissional dos graduados em Ciências Contábeis e Administrativas. No entanto, essa Lei não discrimina as atividades que são de competência exclusiva do contador, não cria um órgão de ordenação e fiscalização profissional, nem determina sanções ao exercício ilegal da profissão (KRAEMER, 2005).

A entidade que congrega os contadores no Paraguai denomina-se Colégio de Contadores del Paraguay, porém sua matrícula é facultativa, não constituindo em condição necessária para o exercício da profissão, sendo requisito para a atuação, apenas para a formação superior em Contabilidade (OLIVEIRA, 2004). Nesse país, a formação profissional é idealizada como um processo de ensinoaprendizagem e investigação, que representa três etapas de formação: o pré-graduado, o graduado e o pós-graduado, correspondendo a um período que se inicia bem antes do ingresso na universidade e se prolonga até o término da vida ativa do profissional (KRAEMER, 2005).

No que concerne ao graduado, a formação do profissional em Contabilidade deve ser generalista e integral. Esta formação poderá ser alcançada mediante uma combinação harmônica de matérias profissionais com as de respaldo, ou seja, a educação se dá pela combinação de matérias que preparam o profissional, em um curto período, a executar, de forma especializada, suas atividades 
(matérias profissionais) e as que permitem ao graduado a obtenção de conhecimento das técnicas e ferramentas da profissão, o conhecimento geral do ambiente econômico e jurídico de atuação, e o desenvolvimento nas técnicas de comunicação - matérias de respaldo (KRAEMER, 2005). Assim, o currículo de carreira de Contabilidade apresentado pela Universidad Nacional de Asunción é composto de 47 disciplinas, o que corresponde a 10 semestres letivos (FCE UNA, 2009).

\subsubsection{Uruguai}

A profissão de Contador no Uruguai, pelo menos até o momento da pesquisa de Kraemer (2005), não estava regulamentada. Existia, entretanto, alguns dispositivos que tratavam do assunto, como uma Lei de 1917, renovada pelo Decreto № 104/1968, que reserva aos Contadores e Peritos a possibilidade de exercer exclusivamente os cargos que se ocupam da "teneduria de libros", isto é, guardadores de livros (KRAEMER, 2005).

A Lei $N^{\circ} 12.802 / 1960$ contém artigos nos quais se estabelecem sucintamente algumas atuações privativas que podem ter certos profissionais, entre eles os contadores públicos. Essa Lei prevê que os contadores públicos atuem em certificações de balanço e prestações de contas ou relatórios contábeis apresentados perante organismos públicos (URUGUAI, 1960).

No Uruguai, os anos de 1991 e 1993 foram de extrema importância para a Contabilidade, pois foram aprovados os Decretos $\mathrm{N}^{\circ}$ 103/1991 e 240/1993, que reafirmaram a obrigatoriedade de os relatórios contábeis estarem acompanhados de informe emitido por Contadores Públicos e a obrigatoriedade dos balanços, apresentados perante os organismos públicos com pareceres de auditores independentes (KRAEMER, 2005).

Atualmente a entidade que congrega os contadores no Uruguai é o Colégio de Contadores e Economistas do Uruguai. Porém, não é obrigatória a matrícula na entidade para fins de exercício da profissão (OLIVEIRA, 2004). E esse título de Contador Público é outorgado pela Facultad de Ciências Econômicas y de Administración de la Universidad de la República após os alunos terem cursado, pelo menos, 33 disciplinas obrigatórias, o que equivale a 3.183 horas-aula durante o curso (CCEEA, 1990).

\section{METODOLOGIA}

A metodologia utilizada para a realização dessa pesquisa é descritiva documental. Segundo Gil (2006, p. 42), “as pesquisas descritivas têm como objetivo primordial a descrição das características de determinada população ou fenômeno, ou então o estabelecimento de relações entre variáveis", e documental por se basear em documentos já elaborados, mas que não receberam ainda um tratamento analítico (GIL, 2006). Na contextualização do trabalho, fez-se uma pesquisa bibliográfica, baseada em livros, artigos de revista, entre outros. Quanto ao seu objetivo, tem caráter qualitativo.

Inicialmente foi suposto que cada país do MERCOSUL teria uma entidade representante que elaborasse um currículo modelo para os cursos de graduação. No entanto, a Argentina, o Paraguai e o Uruguai não possuem uma resolução nacional quanto às diretrizes curriculares. Sendo assim, ficou estabelecido que seriam analisados os currículos de pelo menos uma instituição de ensino superior de cada País. E a escolha dessa IES foi feita com base na relevância da IES e na disponibilidade da matriz curricular do curso de Ciências Contábeis no seu site, caracterizando uma amostra não aleatória. Assim, o Quadro 2 apresenta as (IES) selecionadas em cada país.

Quadro 2 - IES Pesquisadas em Cada País.

\begin{tabular}{|l|l|}
\hline \multicolumn{1}{|c|}{ País } & \multicolumn{1}{c|}{ IES } \\
\hline Argentina & Facultad de Ciencias Econômicas de la Universidad de Buenos Aires (UBA) \\
\hline Brasil & Faculdade de Economia, Administração e Contabilidade da Universidade de São Paulo (USP) \\
\hline Paraguai & Universidad Nacional de Asunción (UNA) \\
\hline Uruguai & Facultad de Ciências Econômicas y de Administración de La Universidad de La República (Univ. Rep.) \\
\hline
\end{tabular}

Fonte: Elaboração própria (2009). 
A análise dos dados coletados foi feita pela comparação entre as matérias (disciplinas) que compõem os currículos das universidades selecionadas, com as matérias sugeridas pelo Currículo Mundial. Assim, buscou-se no site da UNCTAC a composição do Currículo Mundial e suas áreas de conhecimento. A partir desses dados, foram classificadas as disciplinas das universidades dentro do Currículo Mundial proposto pela ONU/UNCTAC/ISAR, por meio da similaridade, ou proximidade entre os nomes dados às disciplinas. Destaca-se que as disciplinas optativas não foram analisadas.

ANÁLISE DE DADOS

Nesse tópico é apresentada à análise dos dados coletados conforme a metodologia e o referencial teórico abordado na pesquisa. Na Tabela 1, é apresenta a relação entre as matrizes curriculares das instituições selecionadas, com os blocos de conhecimento do Currículo Mundial proposto pela ONU/UNCTAD/ISAR.

Tabela 1 - Similaridade entre os Currículos dos Cursos de Ciências Contábeis das Universidades Estudadas do MERCOSUL com o Currículo Mundial.

\begin{tabular}{|c|c|c|c|c|c|c|c|}
\hline Instituiçõoes & 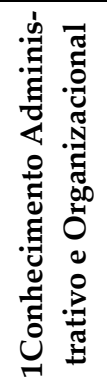 & 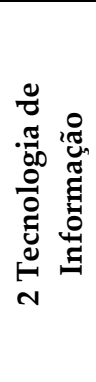 & 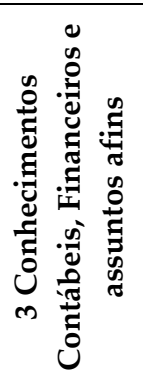 & 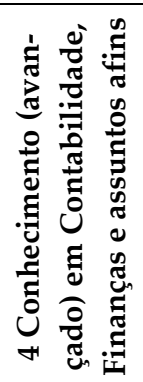 & 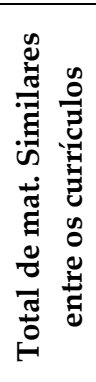 & 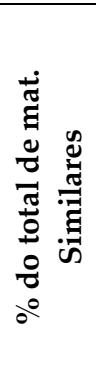 & 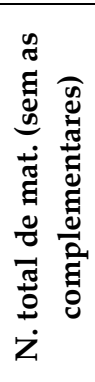 \\
\hline UBA - Argentina & 13 & 1 & 7 & 3 & 24 & 80,00 & 30 \\
\hline USP - Brasil & 10 & 0 & 12 & 7 & 29 & 80,56 & 36 \\
\hline UNA - Paraguai & 14 & 1 & 10 & 7 & 32 & 68,09 & 47 \\
\hline Univ.Rep. - Uruguai & 13 & 0 & 11 & 3 & 27 & 81,82 & 33 \\
\hline Total & 50 & 2 & 40 & 20 & 112 & 76,71 & 146 \\
\hline
\end{tabular}

Fonte: dados da pesquisa

Nessa tabela, estão evidenciados os números de disciplinas que cada universidade continha dentro de cada bloco de conhecimento proposto pelo Currículo Mundial, constando, também, o quanto corresponde, em porcentagem, a quantidade de matérias similares entre o total de disciplinas oferecidas pelas universidades de cada países do MERCOSUL e as similares com o Currículo Mundial (CM), com exceção das disciplinas optativas, conforme metodologia adotada.

O currículo dos cursos de Ciências Contábeis cujos nomes das disciplinas mais se assemelham aos da nomenclatura sugerida pelo CM é o da Facultad de Ciências Econômicas y de Administración de la Universidad de la República (Uruguai), com 81,82\% de similaridade em relação ao número total de disciplinas oferecidas pela universidade. A que apresentou menor similaridade foi a Universidad Nacional de Asunción (Paraguai), pois dentre as 47 matérias obrigatórias oferecidas pelo curso, $68,09 \%$ são correspondente às disciplinas dos blocos de conhecimento sugeridos pelo currículo proposto pela ONU/UNCTAD/ISAR.

A proporção de semelhança entre os nomes das matérias oferecidas pelas quatro universidades selecionadas dos países do MERCOSUL com o Currículo Mundial é alta, pois das 146 disciplinas obrigatórias, em média, 76,71\% constam no Currículo Mundial.

Esse modelo de currículo globalizado proposto pela ONU/UNCTAC/ISAR pode gerar a expectativa de que esta é a atitude mais correta em termos de melhoria da qualidade de ensino. No entanto, a preocupação relacionada à qualidade do ensino deveria se centrar na qualidade da aprendizagem dos discentes. Assim, os currículos deveriam atender às necessidades dos discentes, de acordo com as exigências sociais e educacionais contemporâneas, dando atenção aos conteúdos e à 
forma como estão sendo ensinados, e à utilidade deles para a vida cultural e prática dos alunos. Dessa forma, cada IES deve investir no aperfeiçoamento do currículo e das suas práticas metodológicas, com a participação de todos os setores envolvidos no processo educacional, obtendo, assim, um currículo baseado no modelo misto.

Na Tabela 2 são apresentados, em percentual, os blocos de conhecimento com maior quantidade de disciplinas similares em relação ao total de matérias do Currículo Mundial.

Tabela 2 - Percentual de Similaridade entre Bloco de Conhecimentos e as Matérias das Universidades Pesquisadas

\begin{tabular}{l|c}
\multicolumn{1}{c}{ Blocos de conhecimento } & \% \\
\hline Conhecimento Administrativo e Organizacional & 44,64 \\
Tecnologia da Informação & 1,79 \\
Conhecimentos Contábeis, Financeiros e assuntos afins & 35,71 \\
Conhecimento (avançado) em Contabilidade, Finanças e assuntos afins & 17,86 \\
\hline
\end{tabular}

Fonte: dados da pesquisa

Conforme Tabela 2, percebe-se que o bloco de conhecimento que possui maior similaridade entre o nome das matérias é o de Conhecimentos Administrativo e Organizacional, com 44,64\%. Entretanto, para o bloco de Tecnologia de Informação, as instituições de ensino superior do MERCOSUL estão aquém do sugerido, com apenas 1,79\% de aproximação. Tendo em vista os avanços tecnológicos e crescente necessidade de informação dos últimos anos, isso é preocupante. Quanto os Conhecimentos Contábeis, Financeiros e Assuntos Afins, assim como os Conhecimentos Avançados, possuem proporções respectivamente de $35,71 \%$ e 17,86\% de aproximação.

Através desses percentuais, abaixo de $50 \%$ entre todos os blocos de conhecimentos e as matérias das universidades, pode-se deduzir que as instituições analisadas utilizam como forma de organização do currículo o modelo misto, tendo em vista não adotar exclusivamente o modelo centralizado, administrado e controlado pela ONU/UNCTAC/ISAR, e nem totalmente o modelo descentralizado, conforme foi visto no referencial teórico, que é auto regulamentado pelas instituições de ensino, com a forte atuação de professores, alunos e comunidade onde a instituição se insere, sem a interferência de um órgão central (VEIGA, 2004).

A Tabela 3 apresenta as disciplinas alocadas nas áreas de conhecimento do bloco "Conhecimentos Administrativos e Organizacional", que aparecem com maior frequência nos currículos dos cursos de Ciências Contábeis das universidades pesquisadas.

Tabela 3 - Áreas de Conhecimento mais Frequentes no Bloco "Conhecimento Administrativo e Organizacional".

\begin{tabular}{l|c|c|c|c|c}
\hline \multicolumn{1}{c|}{ Subáreas } & UBA & USP & UNA & Univ. Rep. & Total \\
\hline Economia & 5 & 2 & 2 & 4 & $\mathbf{1 3}$ \\
Métodos quantitativos e estatísticos para as empresas & 4 & 5 & 4 & 4 & $\mathbf{1 7}$ \\
Políticas empresariais, de estruturas organizacionais básicas, e & 2 & 2 & 4 & 1 & $\mathbf{9}$ \\
comportamento organizacional & 2 & 2 & 1 & 4 & 3 \\
Funções e práticas administrativas, e gestão de operações & 2 & 0 & 0 & 0 & $\mathbf{1 0}$ \\
Marketing & 0 & 0 & 0 & 1 & $\mathbf{1}$ \\
Mercados internacionais & $\mathbf{1 3}$ & $\mathbf{1 0}$ & $\mathbf{1 4}$ & $\mathbf{1 3}$ & $\mathbf{5 0}$ \\
\hline Total & & & & & \\
\hline
\end{tabular}

Fonte: dados da pesquisa

Percebe-se que as disciplinas mais frequentes no bloco "Conhecimentos Administrativos e Organizacional" são da subárea de métodos quantitativos e estatísticos para as empresas, com 17 das 50 disciplinas similares ao Currículo Mundial. Seguida pelas áreas de economia e de funções e práticas administrativas e gestão de operações. 
A Tabela 4 contém as áreas de conhecimento do bloco "Tecnologia de Informação", que aparecem somente em duas universidades, a UBA e a UNA, propondo as disciplinas de tecnologia da informação. As demais universidades sugerem disciplinas mais especificas, as quais foram enquadradas no bloco "Conhecimento Contábeis, Financeiros e Assuntos Afins". Tal fato pode ser justificado por ambas as faculdades, tanto a UBA como a UNA, apresentarem um currículo com disciplinas iniciais para diversos cursos, enquanto que o curso de Ciências Contábeis da USP e da Universidad de La República possuírem uma grade curricular específica para seus cursos.

Tabela 4 - Áreas de Conhecimento mais Frequentes no Bloco "Tecnologia de Informação".

\begin{tabular}{l|c|c|c|c|c}
\hline \multicolumn{1}{c|}{ Subáreas } & UBA & USP & UNA & Univ. Rep. & Total \\
\hline Tecnologia de informação & 1 & 0 & 1 & 0 & $\mathbf{2}$ \\
\hline Total & $\mathbf{1}$ & $\mathbf{0}$ & $\mathbf{1}$ & $\mathbf{0}$ & $\mathbf{2}$ \\
\hline
\end{tabular}

Fonte: dados da pesquisa

Os resultados da Tabela 4 demostram a flexibilidade de elaboração dos currículos, permitindo que cada instituição analisada se ajuste à realidade global, regional e local, com a colaboração de professores, alunos e administração.

Na Tabela 5 estão listadas as áreas de conhecimento do bloco "Conhecimentos de Contabilidade, Finanças e Assuntos Afins", bloco que apresentou a segunda maior frequência de disciplinas similares ao CM. As universidades apresentaram maior quantidade de disciplinas de Contabilidade básica e de Direito comercial e empresarial.

Tabela 5 - Áreas de Conhecimento mais Frequentes no Bloco "Conhecimento Contábeis, Financeiros e Assuntos Afins".

\begin{tabular}{l|c|c|c|c|c}
\multicolumn{1}{c|}{ Subáreas } & UBA & USP & UNA & Univ. Rep. & Total \\
\hline Contabilidade básica & 2 & 5 & 0 & 2 & $\mathbf{9}$ \\
Contabilidade financeira & 0 & 0 & 1 & 0 & $\mathbf{1}$ \\
Contabilidade financeira avançada & 0 & 0 & 5 & 1 & $\mathbf{6}$ \\
Contabilidade gerencial - conceitos básicos & 1 & 1 & 1 & 1 & $\mathbf{4}$ \\
Tributação & 0 & 1 & 1 & 2 & $\mathbf{4}$ \\
Sistemas de informações contábeis & 1 & 1 & 0 & 1 & $\mathbf{3}$ \\
Direito comercial e empresarial & 2 & 3 & 1 & 3 & $\mathbf{9}$ \\
Fundamentos sobre auditoria & 1 & 1 & 1 & 1 & $\mathbf{4}$ \\
Finanças empresariais e gestão financeira & 0 & 0 & 0 & 0 & $\mathbf{0}$ \\
Módulo sobre integração do conhecimento: a capstone & 0 & 0 & 0 & 0 & $\mathbf{0}$ \\
\hline Total & $\mathbf{7}$ & $\mathbf{1 2}$ & $\mathbf{1 0}$ & $\mathbf{1 1}$ & $\mathbf{4 0}$ \\
\hline
\end{tabular}

Fonte: dados da pesquisa

A maior frequência de disciplinas similares entre as IES estudadas e o Currículo Mundial no bloco exposto acima talvez seja devido à importância de tais disciplinas no curso de Ciências Contábeis, que independem das características regionais, pois são essenciais ao curso e à formação de bacharéis em Ciências Contábeis. Isso pode explicar esses resultados.

A Tabela 6 apresenta as subáreas do bloco "Conhecimento (avançado) em Contabilidade, Finanças e Assuntos Afins". A área de conhecimento que apresenta maior número de disciplinas similares ao CM é a de finanças empresariais avançadas e administração financeira. Assim, se for analisado o somatório de disciplinas similares ao Currículo Mundial enquadradas nos blocos "Conhecimento em Contabilidade, Finanças e assuntos afins" e "Conhecimento (avançado) em Contabilidade, Finanças e assuntos afins", percebe-se que, do total de matérias similares (112), 60 correspondem às disciplinas relacionadas diretamente a área de Ciências Contábeis. 
Tabela 6 - Áreas de Conhecimento mais Frequentes no Bloco

"Conhecimento (Avançado) em Contabilidade, Finanças e Assuntos Afins".

\begin{tabular}{l|c|c|c|c|c}
\hline \multicolumn{1}{c|}{ Subáreas } & UBA & USP & UNA & Univ. Rep. & Total \\
\hline Demonstrações financeiras avançadas e Contabilidade industrial & 0 & 2 & 0 & 0 & $\mathbf{2}$ \\
Contabilidade gerencial avançada & 1 & 1 & 1 & 1 & $\mathbf{4}$ \\
Tributação avançada & 0 & 0 & 1 & 0 & $\mathbf{1}$ \\
Direito empresarial avançado & 1 & 0 & 1 & 1 & $\mathbf{3}$ \\
Auditoria avançada & 0 & 0 & 2 & 1 & $\mathbf{3}$ \\
Finanças empresariais avançadas e Administração financeira & 1 & 4 & 2 & 0 & $\mathbf{7}$ \\
Estágio Contábil & 0 & 0 & 0 & 0 & $\mathbf{0}$ \\
\hline Total & $\mathbf{3}$ & $\mathbf{7}$ & $\mathbf{7}$ & $\mathbf{3}$ & $\mathbf{2 0}$ \\
\hline
\end{tabular}

Fonte: dados da pesquisa

Isso demonstra que a similaridade entre as disciplinas das IES analisadas e o Currículo Mundial $(\mathrm{CM})$ ocorre com mais frequência nas matérias relacionadas diretamente à área Contábil. Esse resultado evidencia que disciplinas primordiais ao curso são as mais equivalentes, confirmando a utilização de um modelo misto, em que essas IES se baseiam no CM, pois independem das especificidades de cada região, são fundamentais ao conhecimento da Ciência Contábil. Já as demais disciplinas são flexíveis, isto é, são auto regulamentadas pelas instituições de ensino estudadas.

5

\section{CONSIDERAÇÕES FINAIS}

$\mathrm{O}$ atual processo mundial de harmonização e convergência às Normas Internacionais de Contabilidade (NIC) editadas pelo IASB tem gerado preocupações quanto ao ensino mundial do curso de graduação em Ciências Contábeis. A partir do momento em que diversos países do mundo passarem a adotar a mesma linguagem em termos de práticas contábeis, os contadores, em todo o mundo, terão maior facilidade de atuarem profissionalmente fora de seus países.

Tal preocupação fez com que a ONU/UNCTAD/ISAR elaborasse um currículo modelo para esse curso, de modo a servir de referência mundial na elaboração dos projetos político pedagógicos. Contudo, é importante destacar que essa discussão não deve ocorrer de maneira rígida e centralizada, sem levar em consideração as características e necessidades sociais, econômicas e culturais das regiões onde as IES estão inseridas. Assim, apesar de haver a necessidade atual de discussão a respeito do ensino mundial de Contabilidade, não se deve buscar estabelecer um currículo único mundial, mas sim um debate com a participação de todos os envolvidos no processo educativo.

Dessa forma, a criação de um Currículo Mundial para os cursos de Ciências Contábeis, proposta pela ONU/UNCTAD/ISAR, possibilita a formação de um profissional com nível de conhecimento mundial, o que auxilia na harmonização das normas contábeis dos diferentes países. Com isso, a partir dos resultados desta pesquisa foi possível identificar que os percentuais totais das matérias similares entre as universidades estudadas e o Currículo Mundial são altos, ou seja, a grande maioria das disciplinas obrigatórias nas IES são similares àquelas propostas por esse currículo. A Universidad de Buenos Aires apresentou um índice de similaridade de 80,00\%, a Universidade de São Paulo um índice de 80,56\%, a Universidad Nacional de Asunción um índice de 68,09\% e Universidad de La República um índice de $81,82 \%$.

Entretanto, também foi possível verificar que a similaridade entre os blocos de conhecimento e as matérias das universidades estudas é inferior à metade das disciplinas, pois o bloco com maior similaridade foi o de Conhecimento Administrativo e Organizacional, com 44,64\% das disciplinas oferecidas pelos cursos, seguido pelo bloco de Conhecimentos Contábeis, Financeiros e Assuntos Afins, com 35,71\%. O bloco de Conhecimentos Administrativos e Organizacionais pode ter esse percentual justificado pelo fato de que, nas universidades da Argentina, Paraguai e Uruguai, os cursos 
no primeiro ano são voltados para todas as Ciências Sociais, não sendo específico ao curso de Ciências Contábeis, o que acaba exigindo um conhecimento geral em diversas áreas do conhecimento (Administração, Economia, Sociologia, entre outras).

Já as disciplinas que proporcionam o conhecimento das Tecnologias de Informação foram as que apresentaram maior distanciamento daquelas propostas pelo Currículo Mundial, tendo apenas $1,79 \%$ das disciplinas oferecidas pelos cursos similares à proposta da ONU/UNCTAD/ISAR.

Conclui-se, assim, que os currículos dos cursos de Ciências Contábeis das quatro universidades pesquisadas, com relação ao proposto pela ONU/UNCTAD/ISAR, apresentam uma taxa de similaridade de cerca de $76,71 \%$. Portanto, percebe-se que as universidades aqui analisadas estão parcialmente adaptadas ao currículo proposto pela ONU/UNCTAD/ISAR, de forma flexível, levando em consideração as especificidades de cada instituição de ensino e da região onde estão localizadas.

\section{REFERÊNCIAS}

ARGENTINA. Ley 20.488 (Del 23 de mayo de 1973). Normas referentes al ejercicio de las profesiones relacionadas con las Ciencias Económicas. Disponível em: http://www.consejo.org.ar/elconsejo/documentos/ley20488.htm. Acesso em: 26 nov. 2009.

CCEEA - Faculdad de Ciencias Economicas y de Administración de la Universidad de la Republica. Plan de estúdios, 1990. Disponível em: http://www.ccee.edu.uy/ensenian/planest/contador.htm. Acesso em: 26 nov. 2009.

CZESNAT, A. F. O.; CUNHA, J. V. A. Uma análise comparativa entre os currículos dos cursos de ciências contábeis das universidades do estado de Santa Catarina listadas no MEC com o currículo internacional proposto pela UNCTAC/ONU/ISAR. IN: SEMEAD, 12., São Paulo, 2009. Anais... São Paulo, 2009.

ERFURTH, A. E.; DOMINGUES, M. J. C. S. Estrutura curricular do curso de ciências contábeis na universidade de Buenos Aires versus a estrutura curricular proposta pelo ISAR/UNCTAD. IN: Seminário de Ciências Contábeis FURB, 4., Blumenau, 2008. Anais... Blumenau, 2008

FCE UBA - Facultad de Ciencias Económicas de la Universidad de Buenos Aires. Plan de estudios de contador publico: plan 2007. Disponível em: http://web.econ.uba.ar/WAppFCE01. Acesso em: 26 nov. 2009.

FCE UNA - Faculdad de Ciecas Economicas de la Universidad de Nacional Asunción. Malla Curricular. Disponível em: http://www.eco.una.py/malla_cont.html. Acesso em: 26 nov. 2009.

FEA USP - Faculdade de Economia, Administração e Contabilidade da Universidade de São Paulo. Estrutura Curricular. Disponível em: http://www.fea.usp.br/conteudo.php?i=206. Acesso em: 26 nov. 2009.

GIL, A. C. Como elaborar projetos de pesquisa. 4. ed. São Paulo: Atlas, 2006.

KRAEMER, M. E. P. Harmonização dos requisitos do exercício profissional do contabilista nos países que integram o MERCOSUL. GestioPolis.com, março, 2005. Disponível em: http://www.gestiopolis.com/recursos4/docs/fin/harmonia.htm. Acesso em: 26 jan. 2010. 
LEMES, S.; CARVALHO, L. N. G. Comparabilidade entre o resultado em BR GAAP e U.S. GAAP: evidências das companhias brasileiras listadas nas bolsas norte-americanas. Revista Contabilidade \& Finanças, São Paulo, v. 20, n. 50, p. 25-45, maio/ago. 2009.

MRE - MINISTÉRIO DAS RELAÇÕES EXTERIORES (MERCOSUL). Tratado de Assunção. 1991. Disponível em: http://www.mercosul.gov.br/tratados-e-protocolos/tratado-de-assuncao-1/. Acesso em: 10 nov. 2009.

NIYAMA, J. K. Contabilidade Internacional. São Paulo: Atlas, 2009.

OLIVEIRA, M. E. G. Contabilidade internacional: harmonização de princípios e normas contábeis. FACAPE, Petrolina, 2004. Disponível em: http://www.facape.br/socrates/Trabalhos/Contabilidade Internacional.htm. Acesso em: 26 jan. 2010.

POHLMANN, M. C. Harmonização contábil no Mercosul: a profissão e o processo de emissão de normas: uma contribuição. Caderno de Estudos FIPECAFI, São Paulo, n. 12, p. 1-19, set. 1995.

ROSA, P. M. Os sistemas contábeis nos países do MERCOSUL: um estudo sobre o exercício da profissão e as normas e as práticas contábeis na avaliação de elementos do ativo. Dissertação (Mestrado em Engenharia de Produção) - Universidade Federal de Santa Cataria, Santa Cataria, 1998.

UNCTAD - UNITED NATIONS CONFERENCE ON TRADE AND DEVELOPMENT. Revised Model Accounting Curriculum (MC), TD/B/COM.2/ISAR/21, 2003 Disponível em: http://www.uctad.org. Acesso em: 20 out. 2009.

URUGUAI. LEY 12.802, del 30 de noviembre de 1960. Establece normas de ordenamiento financiero. Disponível em: http://www.parlamento.gub.uy/leyes/ley12802.htm. Acesso em: 26 nov. 2009.

VEIGA, I. P. A. Projeto político-pedagógico: uma construção possível. 12. ed. Campinas: Papirus, 2004. 